\title{
Studi Penentuan Aliran Hidrologi Metode Steepest slope dan Lowest height dengan ASTER GDEMV2 dan ALOS PALSAR (Studi Kasus: Gunung Kelud, Jawa Timur)
}

\author{
Akhmad Sigit Arisandy dan Bangun Muljo Sukojo \\ Jurusan Teknik Geomatika, Fakultas Teknik Sipil dan Perencanaan, Institut Teknologi Sepuluh Nopember (ITS) \\ Jl. Arief Rahman Hakim, Surabaya 60111 Indonesia \\ e-mail: bangunms@gmail.com
}

\begin{abstract}
Abstrak-Gunung Kelud memiliki ketinggian 1.731 mdpl dengan kemiringan lebih dari $\mathbf{4 0}^{\circ}$. Gunung Kelud di Kabupaten Kediri, Jawa Timur memiliki tipe erupsi stratovulkan dengan karakteristik letusan eksplosit. Mempunyai nilai volcanic explosive index 4, dengan durasi letusan \pm 12 menit. Letusan Gunung Kelud salah satunya menghasilkan aliran hidrologi yaitu berupa lahar dan lava yang dapat memberikan ancaman tinggi bagi masyarakat sekitar. Data yang digunakan untuk penentuan aliran hidrologi (lahar dan lava) tersebut adalah DEM ASTER GDEMV2 dan ALOS PALSAR. DEM memiliki informasi data ketinggian yang dapat digunakan untuk memodelkan penentuan arah aliran hidrologi. Hasil pemodelannya menyerupai bentuk di lapangan, sehingga dapat digunakan untuk mitigasi bencana. Teknik penentuan aliran hidrologi pada penelitian ini menggunakan metode steepest slope dan lowest height berdasarkan teori aliran hidrologi. Dari hasil arah pemodelan aliran metode steepest slope, arah aliran hidrologi yang dominan dari puncak Gunung Kelud adalah menuju ke arah barat $(\mathbf{2 1 \%})$, utara (19\%), dan selatan $(16 \%)$. Sedangkan untuk metode lowest height lebih dominan menuju ke arah barat $(19 \%)$, barat laut $(18 \%)$, dan barat laut (19\%). Dapat disimpulkan bahwa aliran dominan menuju arah barat, barat laut, barat daya, selatan dan utara. Sedangkan hasil perbandingan akumulasi aliran yang di-overlay dengan data BNPB, pada metode steepest slope dari data DEM ASTER GDEMV2 memiliki kesalahan hasil aliran sebesar $9,81 \%$ sedangkan data DEM ALOS PALSAR 7,29\%. Sedangkan metode lowest height dari data DEM ASTER GDEMV2 memiliki kesalahan hasil aliran sebesar $\mathbf{1 2 , 1 8 \%}$ sedangkan data DEM ALOS PALSAR 11,25\%. Desa yang terdampak letusan Gunung Kelud yaitu untuk Kabupaten Kediri 29 desa, Blitar 26 desa dan Malang 2 desa.
\end{abstract}

Kata Kunci-Aliran Hidrologi, DEM, lowest height, steepest slope

\section{PENDAHULUAN}

Tyai NDONESIA terletak pada pertemuan tiga lempeng benua, yaitu Lempeng Eurasia, Lempeng Pasifik dan Lempeng Australia, konsekuensi dari tumbukan antar lempeng tersebut terbentuk palung samudera, lipatan, punggungan, patahan di busur kepulauan dan sebaran gunung api. Indonesia memiliki 129 gunung api atau $14 \%$ dari gunung api aktif di dunia, yang tersebar dari ujung utara Sumatera, Jawa, Nusa Tenggara, Maluku dan Sulawesi Utara. Jawa Timur adalah salah satu provinsi di Indonesia yang memiliki 7 gunung api aktif, hal ini membuat Jawa Timur merupakan daerah yang memiliki tingkat ancaman bahaya gunung api yang tinggi. Tujuh gunung aktif di Jawa Timur tersebut salah satunya adalah Gunung Kelud dengan status waspada level II terhitung sejak 28 Februari 2014 [1].

Gunung Kelud memiliki tipe letusan berbentuk strato, secara administratif terletak di wilayah Kabupaten Kediri, Kabupaten Blitar dan Kabupaten Malang, Provinsi Jawa Timur. Secara geografis terletak pada posisi $7^{\circ} 56^{\prime} 00^{\prime \prime} \mathrm{LS}, 112^{\circ} 18^{\prime} 30^{\prime \prime}$ BT dengan ketinggian puncak 1.731 meter di atas permukaan laut.

Pemanfaatan data informasi geospasial untuk mendukung sistem peringatan dini bencana alam diyakini sebagai suatu teknik yang dapat memberi kontribusi sangat banyak. Kegiatan ini bertujuan untuk menentukan pola aliran hidrologi Gunung Kelud jika suatu saat terjadi letusan. Oleh karena itu, dalam penelitian ini akan dibuat peta aliran hidrologi yang diperlukan sebagai salah satu komponen sistem peringatan dini sebagai upaya untuk meminimalisir jumlah korban dan kerugian akibat bencana letusan gunung api.

Proses penentuan aliran hidrologi ini berdasarkan teori aliran hidrologi, salah satu kunci untuk menurunkan karakteristik hidrologi permukaan adalah kemampuan untuk menentukan arah aliran (flow direction) dan akumulasi aliran (flow accumulation) dari setiap sel dalam data raster. Hal ini dilakukan dengan menggunakan data Digital Elevation Model (DEM) yaitu, ASTER GDEMV2 dan ALOS PALSAR karena data DEM memiliki data ketinggian yang baik untuk didataran tinggi [3]. Data DEM dapat digunakan untuk mensimulasikan jalur aliran hidrologi berdasarkan nilai kemiringan terbesar dan kemiringan terkecil dengan metode steepest slope dan lowest height. Hasil dengan metode steepest slope dan lowest height dari teori aliran hidrologi, dengan data DEM dapat digunakan sebagai dasar penentuan aliran hidrologi.

\section{METODOLOGI PENELITIAN}

\section{A. Lokasi Penelitian}

Lokasi penelitian tugas akhir adalah di Gunung Kelud yang terletak pada $7^{\circ} 56^{\prime} 00^{\prime \prime} \mathrm{LS}, 112^{\circ} 18^{\prime} 30^{\prime \prime}$ BT. Sedangkan yang secara administratif termasuk dalam wilayah tiga kabupaten, yakni Kabupaten Kediri, Kabupaten Blitar dan Kabupaten Malang, Provinsi Jawa Timur. 


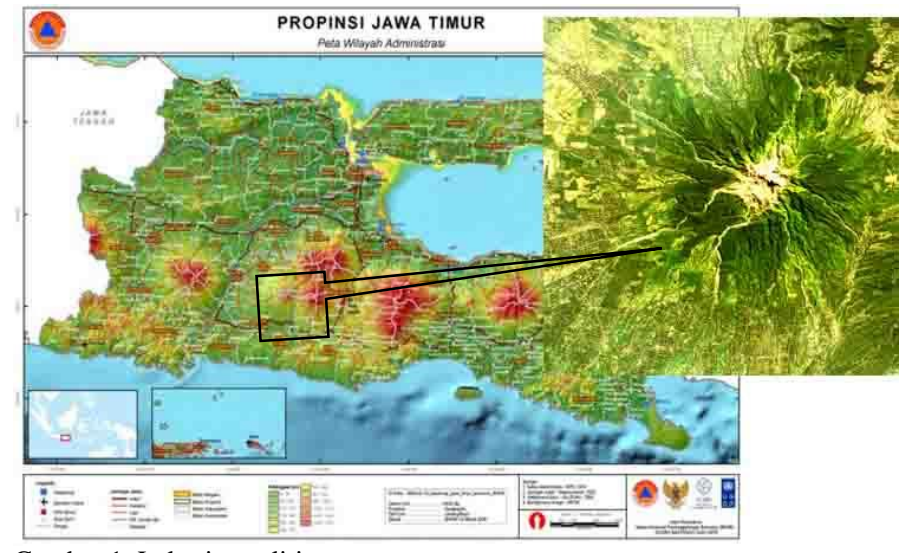

Gambar 1. Lokasi penelitian

\section{B. Data dan Peralatan}

a. Data

Data yang digunakan dalam penelitian tugas akhir ini yaitu:

1. Data Digital Elevation Model (DEM) ASTER Global DEMV2 Wilayah Gunung Kelud tahun 2011.

2. Data DEM ALOS PALSAR Wilayah Gunung Kelud tahun 2010.

3. Peta Administrasi Jawa Timur (RBI) BAKOSURTANAL atau BIG tahun 2000 dengan skala 1:25.000.

4. Peta Kawasan Rawan Bencana (KRB) BNPB Gunung Kelud.

5. Citra Landsat tahun 2015 sesuai dengan daerah penelitian b. Peralatan

Peralatan yang digunakan dalam penelitian tugas akhir ini yaitu:

1. Perangkat Lunak (Sofware):

i. Windows 8.1

ii. Microsoft Office 2013

iii. ArcGIS 10.2.2

2. Peralatan lain untuk survei lapangan :
i. Kamera
ii. GPS Handheld
iii. Alat Tulis

\section{Tahap Pengolahan Data}

Pertama melakukan koreksi radiometrik dan atmospheric pada citra landsat 8 agar memiliki tampilan yang lebih bagus untuk base map dan klasifikasi supervised. Kemudian data DEM ASTER GDEMV2 dan ALOS PALSAR di transformasikan ke dalam koordinat UTM Z 49S. Kemudian untuk menghilangkan depression atau sink pada DEM maka dilakukan proses fill sink. Kemudian croping area penelitian yang mencakup tiga kabupaten yaitu Kabupaten Kediri, Kabupaten Blitar dan Kabupaten Malang. Pembuatan kemiringan lereng dari kedua DEM yang dibagi menjadi 7 kelas.

Pengambilan sempel ketinggian yang di bandingkan dengan RBI dan data pengukuran GPS, kemudian dihitung Nilai RMSE dan korelasi. Setelah itu dengan metode steepest slope dan lowest height ditentukan arah aliran (flow direction) hidrologinya. Kemudian dilakukan pemodelan akumulasi alirannya (flow accumulation). Dari klasifikasi tupan lahan dapat diketahui area luasan tutupan lahan yang terdampak. Hasil aliran di-overlaykan dengan peta KRB dari BNPB dan diberi visualisasi data DEM dengan parameter hilshade. Kondisi ini akan menampilkan data DEM lebih menarik. Setelah jalur aliran lava dibuat, kemudian dapat dihasilkan peta jalur aliran lava Gunung Semeru berdasarkan DEM ASTER GDEMV2 dan ALOS PALSAR.

\section{HASIL DAN PEMBAHASAN}

\section{A. Klasifikasi Supervised}

Hasil analisa tutupan lahan terdapat 10 kelas, namun hanya 8 kelas yang terdampak aliran hidrologi (lahar dan lava) yaitu alang-alang 698,49 ha, semak belukar 3497,16 ha, hutan 2553,34 ha, perkebunan 2110,4 ha, pemukiman 649,39 ha, sawah 2301,01 ha, ladang 2076,1 ha, dan sungai 408,3 ha, dengan luas keseluruhan tutupan lahan terdampak sebesar 14294,18 ha.

\section{B. Hasil Pengambilan Sempel Ketinggian}

Untuk menguji hasil nilai $\mathrm{Z}$ dari kedua data DEM maka menghitung nilai RMSE (Root Mean Square Errors) dan Korelasi Pearson $(r)$ :

$$
\begin{aligned}
& R M S E=\sqrt{\frac{1}{n}} \sum_{i=1}^{n}\left(y_{i}+\breve{y}_{i}\right)^{2} \\
& r=\frac{n \sum X_{i} X_{i-} \sum X_{i} \sum Y_{i}}{\sqrt{n \sum X^{2} i^{-}-\left(\sum X_{i}\right)^{2}} \sqrt{n \sum Y^{2}{ }^{-}-\left(\sum Y_{i}\right)^{2}}}
\end{aligned}
$$

Dari hasil pengambilan sampel $Z$ sebanyak 39 titik, didapatkan bahwa nilai RMSE antara ASTER GDEM dengan RBI memiliki nilai sebesar 3,074, nilai RMSE antara Alos dengan RBI memiliki nilai sebesar 2,781, sedangkan perbandingan nilai RMSE antara DEM ASTER GDEMV2 dan ALOS PALSAR sebesar 4,183. Sedangkan perhitungan Nilai RMSE antara ASTER GDEM dengan data GPS sebesar 3,83 dan ALOS PALSAR dengan data GPS memiliki nilai RMSE sebesar 3,25. Sesuai Perka BIG no. 15 tahun 2014 bahwa pada kelas 1 untuk peta dengan skala 1:100.000 memiliki nilai RMSE vertikal sebesar $20 \mathrm{~m}$ [4]. maka dapat digunakan untuk peta penentuan aliran hidrlogi.

Korelasi sederhana merupakan suatu teknik statistik yang dipergunakan untuk mengukur kekuatan hubungan 2 Variabel dan juga untuk dapat mengetahui bentuk hubungan antara 2 variabel tersebut dengan hasil yang sifatnya kuantitatif.

Dari perhitungan nilai korelasi $(r)$ sehingga di dapatkan nilai korelasi antara ASTER GDEMV2 dengan ALOS PALSAR 0,92, korelasi antara ASTER dengan GPS 0,91 dan sedangkan korelasi antara ALOS PALSAR dengan GPS 0,94. Rentang nilai $0-0,5$ menunjukkan korelasi lemah, $0,5-0,8$ korelasi sedang dan 0,8-1 korelasi kuat [5].

\section{Perbaikan DEM}

Untuk menghilangkan depression atau sink maka diperlukan fill sink pada DEM ASTER dan Alos. Kesalahan yang dimiliki pada data DEM ini disebabkan oleh noise dari citra satelit itu sendiri, seperti kesalahan yang terjadi karena perbedaan sinyal yang diterima. Maka fill sink untuk menghilangkan depression pada data DEM. 


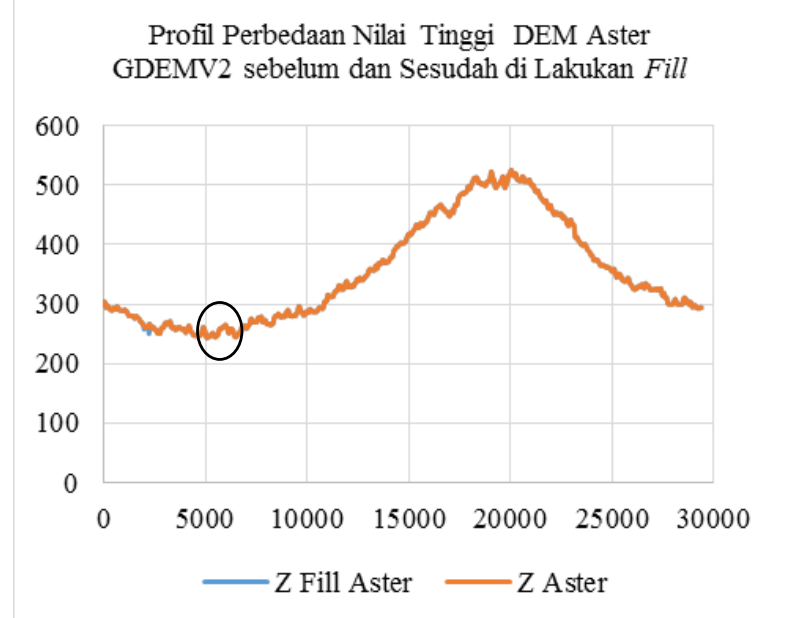

Gambar 2. Grafik Fill sink ASTER GDEMV2

Dari hasil fill sink pada DEM ALOS PALSAR tidak mengalami perubahan antara sesudah dan sebelum dilakukan fill sink, namun pada DEM ASTER mengalami perbedaan setelah dilakukan fill sink sebesar 0,217 m.

\section{Kemiringan Lereng (Slope)}

Hasil dari penentuan kemiringan (Slope) yang diterapkan pada Kedua DEM menenjukan bahwa ada perbedaan antara ketinggian data DEM ASTER GDEMV2 dan ALOS PALSAR.

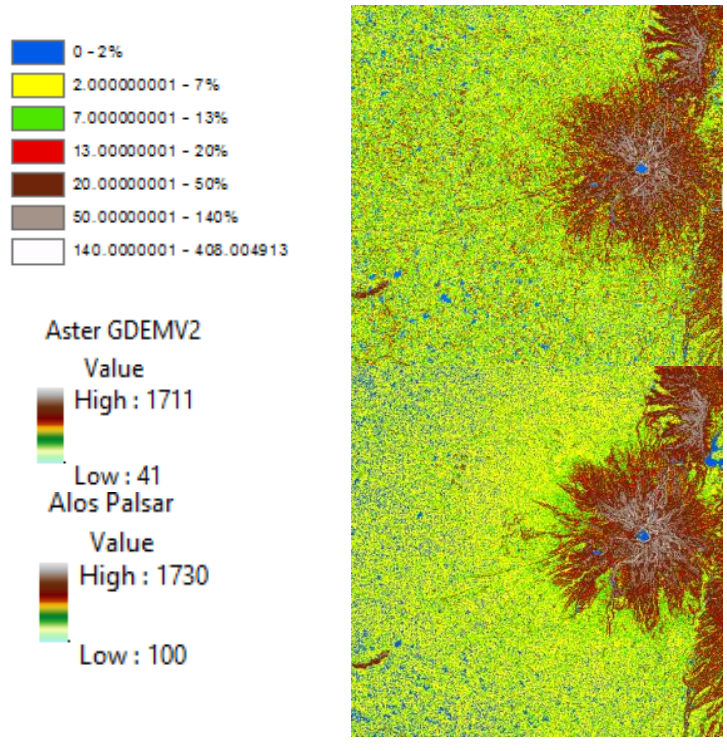

Gambar 3. Kemiringan lereng ASTER (atas), Alos (bawah)

Pada gambar 3 dapat dilihat bahwa Gunung Kelud dari DEM ASTER memiliki tinggi $1.711 \mathrm{mdpl}$, sedangkan DEM Alos memiliki tinggi $1.730 \mathrm{mdpl}$ dan termasuk pegunungan dengan rentang nilai $55-140 \%$ yaitu yang artinya memiliki rentang ketinggian 1.500-3.000 mdpl. Hasil ini sesuai dengan data yang ada pada BNB bahwa Puncak Gunung Kelud 1.731 mdpl [1].

\section{E. Menentukan Arah Aliran (Flow Direction) Steepest Slope} dan Lowes Height

Steepest slope merupakan arah aliran menuju nilai piksel terendah dengan memperhitungkan delapan tetangga sekitar ditambah faktor kemiringan sudut tangensial yang terdapat pada keempat pojok tetangganya [2].

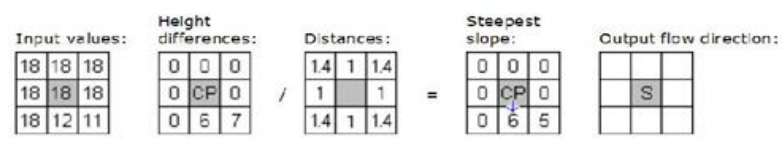

Gambar 4. Algoritma metode steepest sloope

Flow direction yaitu proses penentuan daerah aliran yang menghasilkan informasi arah aliran lereng pada setiap piksel atau Metode penentuan arah aliran sesuai dengan arah mata angin. Arah aliran ini meliputi N (North), E (East), W (West), S (South), NE (North east), NW (Nortwest), SE (SourtEast), SW (Southwest) [3].

Tabel 1.

Flow direction metode steepest slope

\begin{tabular}{|c|c|c|c|}
\hline $\begin{array}{c}\text { Direction } \\
\text { Code }\end{array}$ & Direction & $\begin{array}{c}\text { ASTER } \\
\text { GDEM }\end{array}$ & $\begin{array}{c}\text { ALOS } \\
\text { PALSAR }\end{array}$ \\
\hline 1 & Timur & $13 \%$ & $10 \%$ \\
\hline 2 & Tenggara & $9 \%$ & $7 \%$ \\
\hline 4 & Selatan & $16 \%$ & $14 \%$ \\
\hline 8 & Barat Daya & $12 \%$ & $11 \%$ \\
\hline 16 & Barat & $17 \%$ & $21 \%$ \\
\hline 32 & Barat Laut & $12 \%$ & $12 \%$ \\
\hline 64 & Utara & $14 \%$ & $19 \%$ \\
\hline 128 & Timur Laut & $8 \%$ & $6 \%$ \\
\hline \multicolumn{2}{|c|}{ Jumlah Piksel(\%) } & $100 \%$ & $100 \%$ \\
\hline
\end{tabular}

Hasil dari pengolahan tahap flow direction metode steepest slope, arah aliran hidrologi yang dominan dari puncak Gunung Kelud adalah menuju ke arah barat, utara, dan selatan. Ditunjukkan dengan presentasi arah aliran dari jumlah pixcel.

Sedangkan lowest height merupakan metode penentuan pola aliran hidrologi yang hanya mempertimbangkan delapan tetangga sekitar untuk menuju ke nilai piksel terendah [2].

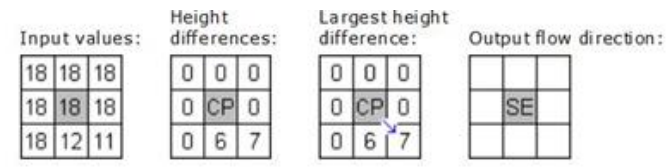

Gambar 5. Algoritma metode lowest height

Tabel 5.

Flow direction metode lowest height

\begin{tabular}{|c|c|c|c|}
\hline $\begin{array}{c}\text { Direction } \\
\text { Code }\end{array}$ & Direction & $\begin{array}{c}\text { ASTER } \\
\text { GDEMV2 }\end{array}$ & $\begin{array}{c}\text { ALOS } \\
\text { PALSAR }\end{array}$ \\
\hline 1 & Timur & $9 \%$ & $10 \%$ \\
\hline 2 & Tenggara & $15 \%$ & $10 \%$ \\
\hline 4 & Selatan & $9 \%$ & $17 \%$ \\
\hline 8 & Barat Daya & $19 \%$ & $14 \%$ \\
\hline 16 & Barat & $11 \%$ & $19 \%$ \\
\hline 32 & Barat Laut & $18 \%$ & $14 \%$ \\
\hline 64 & Utara & $8 \%$ & $10 \%$ \\
\hline 128 & Timur Laut & $11 \%$ & $6 \%$ \\
\hline \multicolumn{2}{|c|}{ Jumlah Piksel } & $100 \%$ & $100 \%$ \\
\hline
\end{tabular}

Hasil dari pengolahan tahap flow direction metode lowest height, arah aliran hidrologi yang dominan dari puncak Gunung Kelud adalah menuju ke arah barat, barat laut, dan barat daya. Ditunjukkan dengan presentasi arah aliran dari jumlah pixel.

F. Memodelkan Arah Akumulasi (Flow Accumulation) Steepest Slope dan Lowest Height

Fungsi ini memodelkan mengenai jumlah akumulasi aliran air yang terjadi pada suatu wilayah tertentu. Sebagai hasil ukur akan terdapat nilai akumulasi air yang biasanya juga identik dengan aliran hidrologi yang sebenarnya di lapangan. Kemudian 
didapatkan hasil akumulasi aliran dalam bentuk 2 dimensi yang di overlay dengan citra Data DEM ASTER GDEMV2 dan ALOS PALSAR.

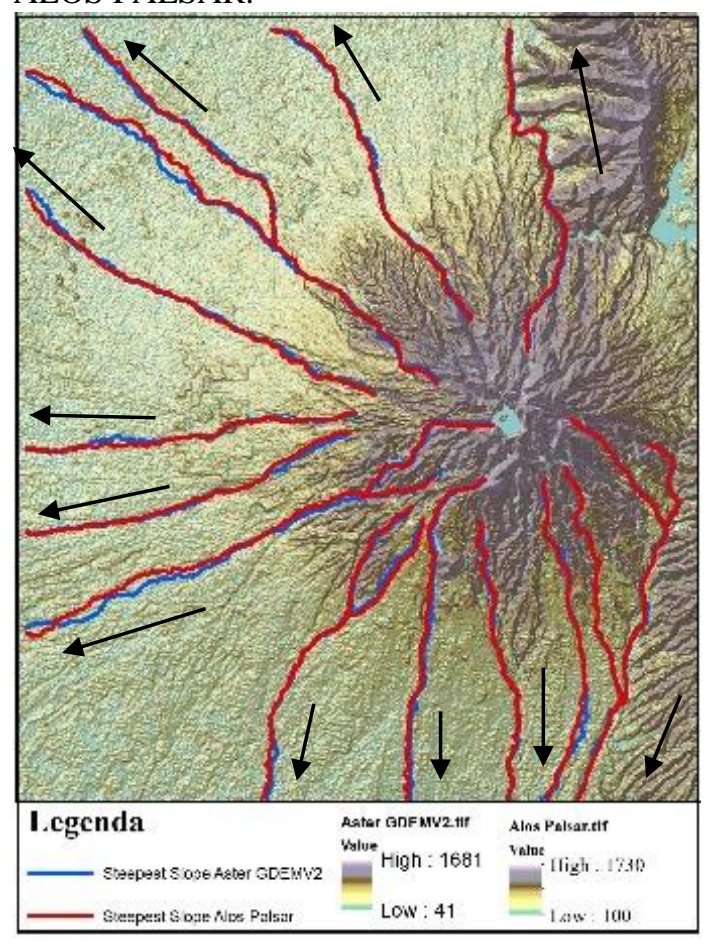

Gambar 6. Akumulasi aliran metode steepes slope

Hasil aliran yang dimodelkan dengan yang di overlay dengan KRB dari BNPB bahwa metode steepest slop dari data DEM ASTER GDEMV2 memiliki kesalahan hasil aliran sebesar 9,81\% sedangkan data DEM ALOS PALSAR 7,29\%.

Dari flow accumulation metode lowest height menghasilkan 12 jalur aliran hidrologi dan kemudian hasilnya di-overlay dengan KRB.

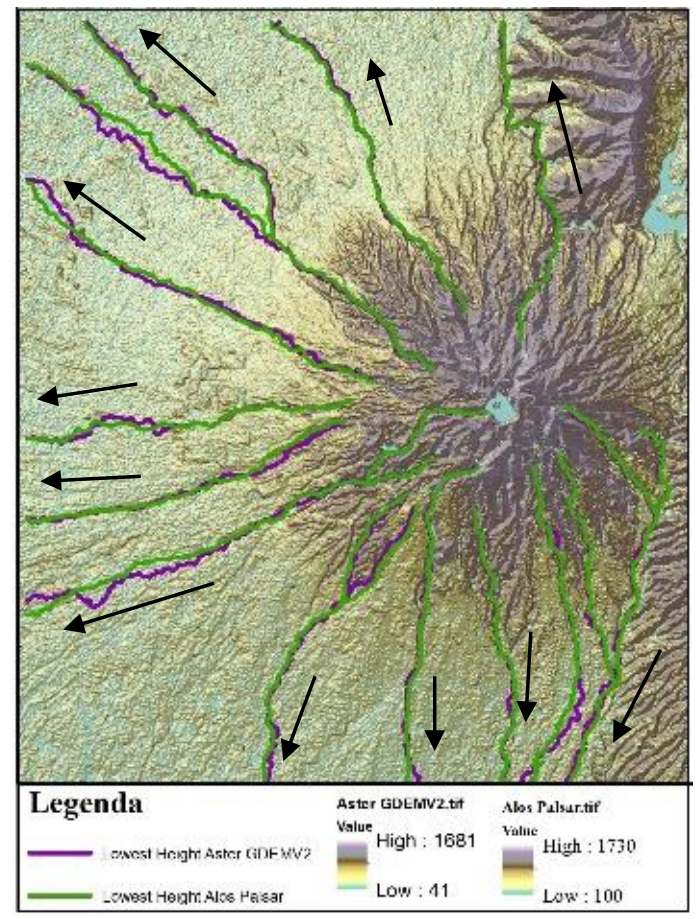

Gambar 7. Akumulasi aliran metode lowest height
Dari flow accumulation metode lowest height menghasilkan 12 jalur aliran hidrologi. Hasil aliran yang dimodelkan dengan yang di overlay dengan KRB dari BNPB bahwa metode lowest height dari data DEM ASTER GDEMV2 memiliki kesalahan hasil aliran sebesar 12,18\% sedangkan data DEM ALOS PALSAR $11,25 \%$.

\section{G. Overlay}

Tahap Akhir (Overlay dan Pembuatan Peta Jalur Aliran Hidrologi (Lahar dan Lava) Gunung Kelud) data-data yang sudah diolah kemudian di-overlay-kan menggunakan software ArcGIS 10.2.2 dengan syarat sistem proyeksi dari peta-peta yang akan di-overlay-kan harus sama. Data tersebut meliputi vektor peta tutupan lahan, DEM ASTER GDEMV2 dan ALOS PALSAR, vektor layer-layer terpilih dari peta Peta Kawasan Rawan Bencana (radius dan aliran lahar). Proyeksi yang digunakan dalam peta ini sesuai dengan peta dasarnya yaitu sistem proyeksi Universal Transverse Mercator (UTM) Zona 49 S dengan datum WGS 1984. Skala peta yang digunakan yaitu 1:100.000. Adapun unsur-unsur yang terdapat pada peta ini antara lain:

a. Jalur Aliran Lava dari Peta Rupa Bumi Indonesia (sumber: pemodelan hidrologi metode steepest slope dan lowest heights software ArcGIS 10.2.2.)

b. Kawasan Rawan Bencana Lahar dan Lava Gunung Kelud (sumber: Peta Kawasan Rawan Bencana skala 1 : 60.000 terbitan Badan Nasional Penanggulangan Bencana)

c. Batas Administrasi (tahun 2010) (sumber: InaGeoportal terbitan Badan Informasi Geospasial)

d. Kontur (tahun 2000) (sumber: InaGeoportal terbitan Badan Informasi Geospasial)

e. Sungai (sumber: InaGeoportal terbitan Badan Informasi Geospasial)

f. Tutupan Lahan (sumber: InaGeoportal terbitan Badan Informasi Geospasial)

g. Landsat 8 LO81180662015183RPI00 (sumber : USGS earth Explorer)

h. DEM ASTER GDEMV2 Tahun 2011 (sumber: gdem.ersdac.jspacesystems.or.jp)

i. DEM ALOS PALSAR Tahun 2010 (sumber: Satelite Alaska Facility)

j. Tampilan Hilshade dari DEM ALOS PALSAR dengan $\mathrm{z}$ limit 1,5 . 


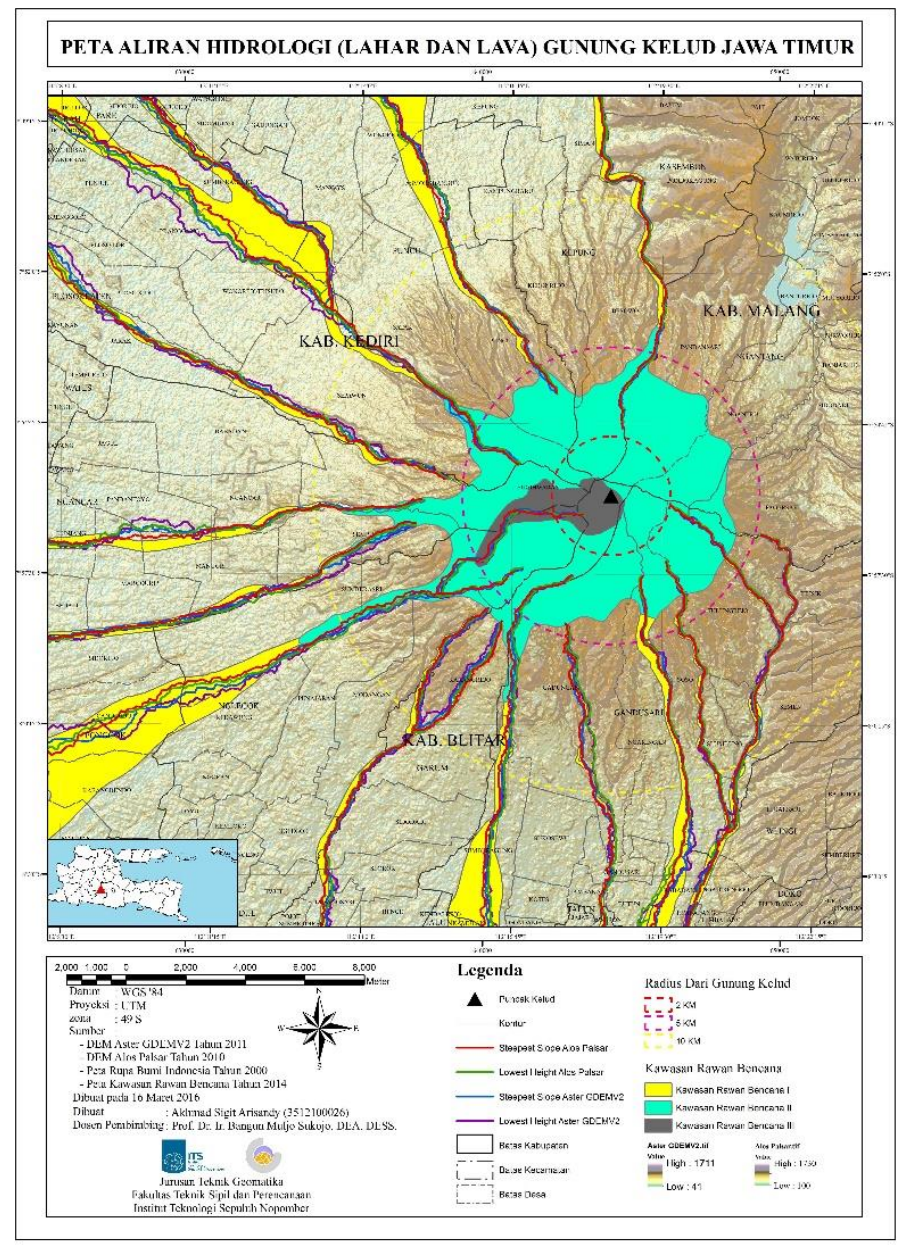

Gambar 8. Peta aliran hidrologi (lahar dan lava) Gunung Kelud

\section{KESIMPULAN DAN SARAN}

Kesimpulan dari Penelitian ini adalah:

a. Dari hasil penentuan aliran hidrologi menggunakan Metode steepest slope dan lowest height, didapatkan nilai arah aliran utara $19 \%$, barat laut $18 \%$, barat $21 \%$, barat daya $19 \%$ dan Selatan 17\%. Nilai ini sesuai dengan bentuk Gunung Kelud yang berbukit di sebelah timur, sedangkan dibagian barat, utara dan selatan berbentuk lereng. Sehingga aliran (lahar dan lava) yang terbentuk menuju ke arah barat, utara dan selatan.

b. Dari hasil analisa aliran metode steepest slope memiliki akurasi yang baik di bandingkan dengan metode lowest height, dapat dilihat dari hasil alian akumulasi (flow accumulation) yang di overlay menunjukkan hasil bahwa aliran yang dimodelkan dengan metode steepest slope dari data DEM ASTER GDEMV2 memiliki kesalahan hasil aliran sebesar 9,81\% sedangkan data DEM ALOS PALSAR 7,29\%. Sedangkan metode lowest height dari data DEM ASTER GDEMV2 memiliki kesalahan hasil aliran sebesar $12,18 \%$ sedangkan data DEM ALOS PALSAR 11,25\%. Hasil analisa tutupan lahan terdapat 10 kelas, namun hanya 8 kelas yang terdampak aliran hidrologi (lahar dan lava) yang paling besar semak belukar 3.497,16 ha, dan area yang paling kecil area sungai 408,3 ha, dan dengan luas keseluruhan tutupan Lahan terdampak sebesar 14.294,18 ha.
Kemudian saran untuk rekomendasi penelitian selanjutnya mengingat pentingnya mitigasi bencana dari letusan Gunung api maka penelitian ini dapat dikembangkan lagi untuk memodelkan jalur aliran hidrologi (lahar dan lava) yang lebih akurat, untuk mendukung mitigasi bencana perlu adanya citra resolusi tinggi seperti citra ikonos, quickbird atau Pleiades.

\section{PENUTUP}

Penulis menyadari bahwa laporan ini masih banyak kekurangan baik dalam penulisan maupun isi dari paper ini, karena itu kami sangat mengharapkan saran dan kritik yang membangun guna perbaikan kelak. Akhir kata, penulis menyampaikan banyak terima kasih semoga Penelitian Tugas Akhir ini dapat bermanfaat untuk mahasiswa Teknik Geomatika FTSP-ITS.

\section{DAFTAR PUSTAKA}

[1] Buku Kelud Seri Letusan 2007, Pusat Vulkanologi dan Mitigasi Bencana Geologi, 2007.

[2] Ilwis. (2009). Hydrologi, New York.

[3] Julzarika, A. I. (2010). Pemanfaatan DEM ALOS PALSAR, DEM SRTM dan Citra Landsat untuk Mengetahui Potensi Longsor (Studi Kasus: Kabupaten Purworejo - Provinsi Jawa Tengah). INDRAJA LAPAN VOL I, NO 1, 6-12.

[4] PERKA BIG, no 15 tahun 2014.

[5] Sujana, (2002). Korelari Pearson. 